\title{
Revision of the Rainfall Intensity Duration Frequency Curves for the City of Kumasi-Ghana
}

\author{
Sulemana Abubakari ${ }^{1 *}$, Kwabena Antwi Kusi ${ }^{2}$, and Dong Xiaohua ${ }^{1}$ \\ ${ }^{*}$ College of Hydraulic and Environmental Engineering, China Three Gorges University, No. 8, Daxue Road, \\ Yichang, Hubei, China. \\ ${ }^{2}$ Sunyani Technical University, P.O.Box SN 206, Sunyani-Brong Ahafo Region, Ghana.
}

\begin{abstract}
This work involves the revision of the Rainfall Intensity Duration Frequency (IDF) Curves for the city of Kumasi. Annual Maximum Rainfall depths of various durations over twenty-two years were obtained from the Ghana Meteorological Services. The data set was then subjected to frequency analysis to determine the distribution of which best characterize the data set. The annual maximum series were found to be drawn from the Gumbel distribution whose parameters were computed by fitting the statistics to the data. The Chi-square test and the Kolmogorov-Smirnov test prove the appropriateness of the fitting. Since the data available was only 22 years, IDF values for return periods higher than 22 years were obtained using frequency factors. The IDF estimates resulting from this work have been compared with the existing IDF curves prepared by J.B Danquah. The results show that for shorter durations (12 $\mathrm{min}$ and $24 \mathrm{~min}$ ), the new IDF Curves give higher intensities for the same return period; the percentage increase ranges between $2 \%$ and $25 \%$, whiles for longer durations $(42 \mathrm{~min}, 1 \mathrm{hr}$, $2 \mathrm{hr}, 3 \mathrm{hr}, 6 \mathrm{hr}, 12 \mathrm{hr}$ and $24 \mathrm{hr}$ ), the new IDF Curves give lower intensities for the same return period with the percentage decrease ranging between $3 \%$ and $49 \%$ when compared with the existing J.B Danquah IDF Curves. This might be as a result of low precipitation trends for shorter durations and high precipitation trends for longer durations in 1970s and before. These therefore call for the revision and updating of the existing IDF Curves for all the major cities and towns in Ghana to take into account the effect of climate change.
\end{abstract}

Keywords: IDF Curves, Gumbel Distribution, Annual Maximum Series, Climate Change, Rainfall Intensity

Date of Submission: 18 January $2017 \quad$ Date of Accepted: 05 February 2017

\section{INTRODUCTION}

The design of any civil engineering infrastructure requires a comprehensive understanding of the intended purpose of the structure and the physical environment in which it would operate. In the management of storm water in a municipality, the dimensions of various components of the infrastructure system are based on the return period of heavy rainfall events. This information is often expressed as Intensity-Duration-Frequency (IDF) curves obtained from a statistical study of extreme events. The IDF curves are empirical relationships that relate the rainfall intensity, the duration and the return period in a given catchment area.

The establishment of such relationships was done as early as 1932 by Chow [1] and Dupont and Allen [2]. Since then, a lot of these curves have been developed in many parts of the world. Example Chen [3] developed a simple method to obtain a generalised rainfall IDF formula for any location in the United States using three isopluvial maps of the U.S Weather Bureau. Yu et al. [4] also developed regional IDF relations for non-recording sites based on scaling theory using the hypothesis of piecewise simple scaling combined with the Gumbel distribution. In Africa, Mohymont et al. [5] assessed IDF-curves for precipitation for three stations in Central Africa and proposed more physically based models for the IDF-curves, Oyebande [6] established IDF curves for Nigeria, similarly, Dankwa [7] developed IDF curves for various towns and cities in Ghana.

The normal balance of the earth's hydrological cycle has been altered due to the changes in temperature and precipitation patterns. Projections from climate models suggest that the probability of occurrence of intense rainfall in future will increase due to the increase in green house gas emissions [8]. The design standards at present are based on historical climate information. Under a changing climate, it has become a priority for municipalities to search for appropriate procedures in the planning and management of water resources infrastructure to deal with changing climatic conditions [9].

Rainfall intensity is an important parameter for the determination of peak flow at a point in a catchment, which is used for the design of drainage structures. The IDF curves developed by Dankwa [7] is what is used in Ghana for the design of drainage structures in various cities. These IDF curves were developed based on the rainfall data 
available at that time. One of the main assumptions in the creation of these curves was that the rainfall data was stationary. That is, climatic trends and variability have negligible effects on the curves. But as has been proved in recent history, climatic variability and trends do exist and their effects on precipitation have not been negligible. Climate change has lead to droughts and floods around the world, and long term trends in rainfall, both increases and decreases, have been seen in different parts of the world including Ghana. There is therefore a possibility that the rainfall intensities used by Dankwa [7] for the development of the IDF curves might have changed. The IDF curves developed by Dankwa [7] have not been revised or updated, however, drainage engineers in Ghana still rely on these curves for their designs. This might lead to over-design or under-design due to the changes in climatic conditions that might have occurred after 1974. Over-designing leads to economic losses as bigger structures are designed whereas under-designing leads to drains of inadequate capacity leading to increased incidents of flooding. In both cases economic losses are incurred.

To reduce economic losses due to over design or under design of drainage structures that might occur using IDF curves developed by Dankwa [7], there is therefore the need for its revision. The main objective of this project therefore is to develop IDF curves for Kumasi based on additional available rainfall information and verify the validity of the existing IDF curves developed by Dankwa [7]. It is hoped that this research work will catapult further research works into revision and updating of the existing IDF Curves for all the major cities and towns in Ghana to take into account the effect of climate change.

\section{MATERIALS AND METHODS}

2.1 Study Area

Kumasi (Fig. 1) is a city in southern central Ghana's Ashanti region. Kumasi is the second largest city in Ghana also the capital of the Ashanti region.

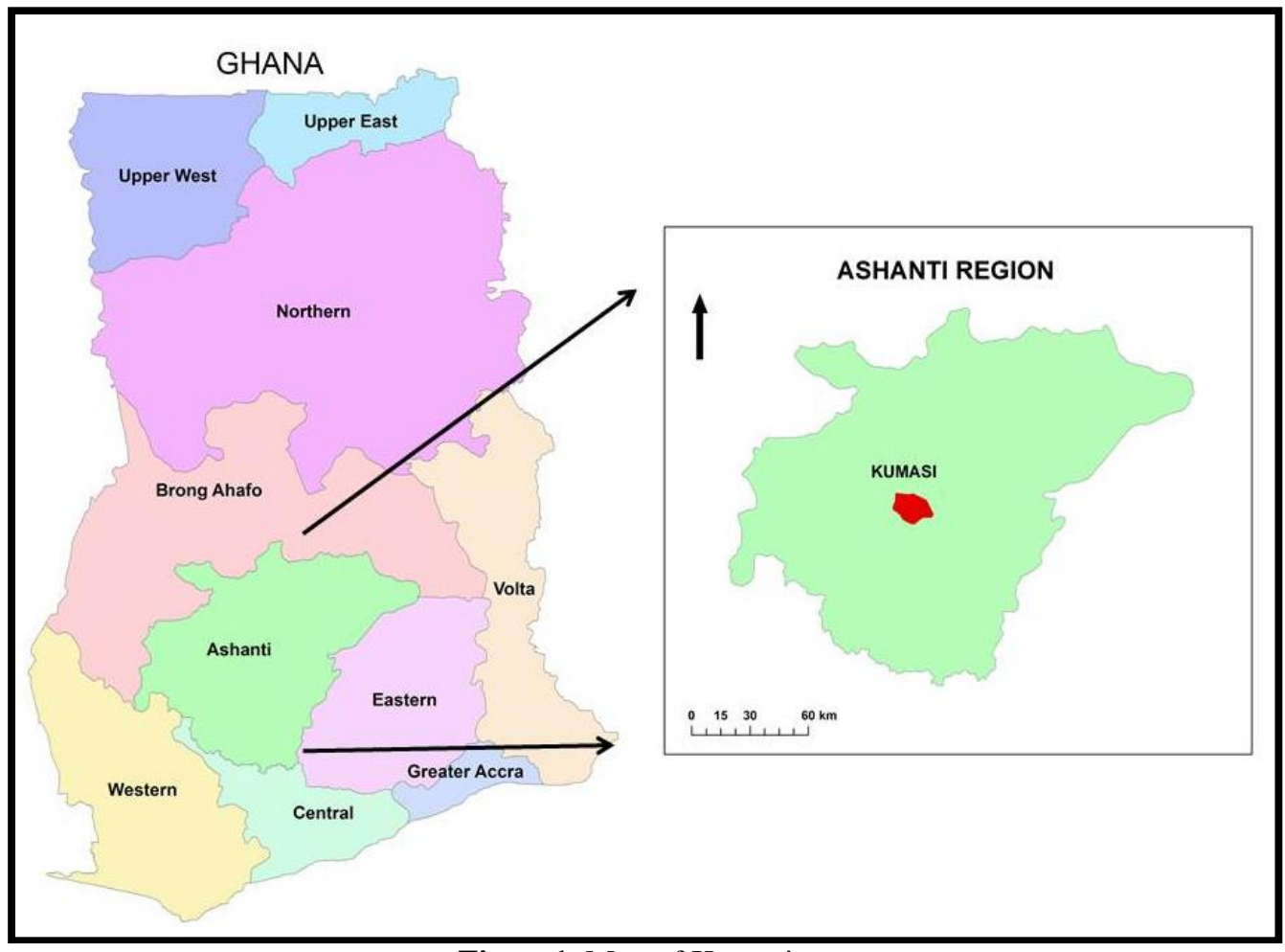

Figure1. Map of Kumasi

The climate is typically tropical, with total annual rainfall of about $1400 \mathrm{~mm}$, the average maximum and minimum temperatures are about $35^{\circ} \mathrm{C}$ and $23^{\circ} \mathrm{C}$ which occurs in February and August respectively [10]. The potential evapotranspiration (PET) is estimated at $1450 \mathrm{~mm} / \mathrm{y}$. The average humidity during the wet season is typically high $(86 \%)$ and falls to about $57 \%$ in the dry period [11]. The major rivers and streams in Kumasi include Subin, Wewe, Susan, Aboabo, Oda, Owabi, Suntreso, Akrubu, Acheamponmene and Asuoyeboa.

\subsection{Data Collection}


The data used in this study was obtained from the Ghana meteorological Services Department. The data consists of annual maximum series (AMS) of rainfall depth over a period of twenty-two years for nine (9) laps of time: $12 \mathrm{~min}, 24 \mathrm{~min}, 42 \mathrm{~min}$, 1hour, 2hours, 3hours, 6hours, 12 hours, and 24 hours.

Table 1: Summary of Data Gathered

\begin{tabular}{l|l}
\hline Duration(hrs) & No. of years with some records \\
\hline 0.2 & 22 \\
0.4 & 22 \\
0.7 & 22 \\
1.0 & 22 \\
2.0 & 22 \\
3.0 & 21 \\
6.0 & 20 \\
12.0 & 19 \\
24.0 & 18 \\
\hline
\end{tabular}

\subsection{Development of IDF Curves}

The data set was subjected to frequency analysis to determine the distribution of which best characterize the data set. The frequency of the rainfall is usually defined with reference to the annual maximum series, which consists of the largest values observed in each year. The annual maximum series were found to be drawn from the Gumbel distribution whose parameters were computed by fitting the statistics to the data. The fitting involves calculating

the $1,2,5,10,20,30$ and 50 return intervals for each duration. Frequency precipitation $P_{T}$ (in $\mathrm{mm}$ ) for each duration with a specified return period $\operatorname{Tr}$ (in year) is given by:

$P_{T}=P_{a v e}+K S$

Where $K$ is the Gumbel frequency given by:

$-\frac{\sqrt{6}}{\pi}\left\{0.577216+\operatorname{In}\left[\operatorname{In} \frac{T}{T-1}\right]\right\}$

For $\operatorname{Tr}<2$ years, $K$ is given by:

$$
-\frac{6}{\sqrt{\pi}} \times\left\lfloor 0.5772-\operatorname{In} T+\frac{1}{2 \times T}+\frac{1}{24 \times T^{2}}+\frac{1}{8 \times T^{3}}\right\rceil \text {. }
$$

In utilizing Gumbel's distribution, the arithmetic average in Eq. (1) is used:

$$
P_{\text {ave }}=\frac{1}{n} \sum_{i=1}^{n} P_{i}
$$

Where $P_{i}$ is the individual extreme value of rainfall and $n$ is the number of events or years of rainfall records.

The standard deviation $(S)$ in equation (1) is given by:

$S=\left\lceil\frac{1}{n-1} \sum_{i=1}^{n}\left(P_{i}-P_{\text {ave }}\right)^{2}\right\rceil^{1 / 2}$

The rainfall intensity, $I_{T}$ (in $\mathrm{mm} / \mathrm{hr}$ ) for a particular return period, $T$ is then obtained by:

$$
I_{T}=\frac{P_{T}}{t_{d}}
$$


The IDF Curves were then developed by plotting the rainfall intensity values, $I_{T}$ against corresponding durations, $t_{d}$ for the different return periods.

\section{RESULTS AND DISCUSSION}

\subsection{IDF Curves for the City of Kumasi}

From the raw data, the maximum precipitation $P_{i}$ and the statistical variables (average and standard deviation) for each duration, $t_{d}(12 \mathrm{~min}, 24 \mathrm{~min}, 42 \mathrm{~min}, 60,1 \mathrm{hr}, 2 \mathrm{hr}, 3 \mathrm{hr}, 6 \mathrm{hr}, 12 \mathrm{hr}$ and $24 \mathrm{hr}$ ) were computed. Table 2 shows the computed frequency precipitation $\left(P_{T}\right)$ values and intensities $\left(I_{T}\right)$ for different return periods

Table 2: Computed frequency precipitation and Intensity values for different durations and return periods for the City of Kumasi.

\begin{tabular}{|c|c|c|c|c|c|c|c|c|c|}
\hline \multirow{5}{*}{$\begin{array}{l}\mathrm{Tr} \\
\text { (year) }\end{array}$} & \multicolumn{9}{|c|}{ Computed Precipitation (PT) and Intensity (IT) using Gumbel Method } \\
\hline & & & Duration & & & & & & \\
\hline & \multicolumn{3}{|l|}{$12 \mathrm{~min}$} & \multicolumn{3}{|l|}{$24 \mathrm{~min}$} & \multicolumn{3}{|l|}{$42 \mathrm{~min}$} \\
\hline & \multicolumn{2}{|c|}{ Pave $=26.719$} & \multirow{2}{*}{$\begin{array}{l}\mathrm{S}=7.786 \\
\mathrm{IT}(\mathrm{mm} / \mathrm{hr})\end{array}$} & \multicolumn{2}{|l|}{ Pave $=39.629$} & $S=12.025$ & \multicolumn{2}{|c|}{ Pave $=44.709$} & \multirow{2}{*}{$\begin{array}{l}\mathrm{S}=11.248 \\
\begin{array}{l}\mathrm{IT}(\mathrm{mm} / \mathrm{h} \\
\mathrm{r})\end{array}\end{array}$} \\
\hline & $K$ & PT & & $K$ & PT & $\mathrm{IT}(\mathrm{mm} / \mathrm{hr})$ & $K$ & PT & \\
\hline 1 & -0.970 & 19.8 & 99.15 & -0.970 & 28.0 & 69.9 & -0.970 & 33.8 & 48.3 \\
\hline 2 & -0.164 & 25.4 & 127.2 & -0.164 & 37.7 & 94.2 & -0.164 & 42.9 & 61.2 \\
\hline 5 & 0.719 & 32.3 & 161.6 & 0.719 & 48.3 & 120.7 & 0.719 & 52.8 & 75.4 \\
\hline 10 & 1.305 & 36.9 & 184.4 & 1.305 & 55.3 & 138.3 & 1.305 & 59.4 & 84.8 \\
\hline 20 & 1.866 & 41.3 & 206.3 & 1.866 & 62.1 & 155.2 & 1.866 & 65.7 & 93.9 \\
\hline 30 & 2.189 & 43.8 & 218.8 & 2.189 & 66.0 & 164.9 & 2.189 & 69.3 & 99 \\
\hline \multirow[t]{3}{*}{50} & 2.592 & 46.9 & 234.5 & 2.592 & 70.8 & 177 & 2.592 & 73.9 & 105.5 \\
\hline & \multicolumn{3}{|l|}{$1 \mathrm{hr}$} & \multicolumn{3}{|l|}{$2 \mathrm{hr}$} & \multicolumn{3}{|l|}{$3 \mathrm{hr}$} \\
\hline & \multicolumn{2}{|c|}{ Pave $=59.513$} & $S=16.547$ & \multicolumn{2}{|l|}{$\begin{array}{l}\text { Pave=67.1 } \\
62\end{array}$} & $S=20.588$ & \multicolumn{2}{|c|}{ Pave $=66.360$} & $\begin{array}{l}S=18.56 \\
8\end{array}$ \\
\hline 1 & -0.970 & 43.5 & 43.5 & -0.970 & 47.2 & 23.6 & -0.970 & 48.4 & 16.2 \\
\hline 2 & -0.164 & 56.7 & 56.7 & -0.164 & 63.8 & 31.9 & -0.164 & 63.3 & 21.1 \\
\hline 5 & 0.719 & 71.3 & 71.3 & 0.719 & 82 & 41 & 0.719 & 79.8 & 26.6 \\
\hline 10 & 1.305 & 81 & 81 & 1.305 & 94 & 47 & 1.305 & 90.4 & 30.2 \\
\hline 20 & 1.866 & 90.3 & 90.3 & 1.866 & 105.6 & 52.8 & 1.866 & 101.1 & 33.7 \\
\hline 30 & 2.189 & 95.6 & 95.6 & 2.189 & 112.2 & 56.1 & 2.189 & 107.1 & 35.7 \\
\hline \multirow[t]{3}{*}{50} & 2.592 & 102.3 & 102.3 & 2.592 & 120.6 & 60.3 & 2.592 & 221.7 & 38.2 \\
\hline & \multicolumn{3}{|l|}{$6 \mathrm{hr}$} & \multicolumn{3}{|l|}{$12 \mathrm{hr}$} & \multicolumn{3}{|l|}{$24 \mathrm{hr}$} \\
\hline & \multicolumn{2}{|c|}{ Pave $=66.562$} & $S=16.789$ & \multicolumn{2}{|l|}{$\begin{array}{l}\text { Pave }=66.5 \\
78\end{array}$} & $\mathrm{~S}=21.053$ & \multicolumn{2}{|c|}{ Pave $=59.554$} & $\begin{array}{l}S=19.39 \\
3\end{array}$ \\
\hline 1 & -0.970 & 50.4 & 8.4 & -0.970 & 45.6 & 3.8 & -0.970 & 40.8 & 1.7 \\
\hline 2 & -0.164 & 63.6 & 10.6 & -0.164 & 63.6 & 5.3 & -0.164 & 55.2 & 2.3 \\
\hline 5 & 0.719 & 78.6 & 13.1 & 0.719 & 81.6 & 6.8 & 0.719 & 74.4 & 3.1 \\
\hline 10 & 1.305 & 88.2 & 14.7 & 1.305 & 93.6 & 7.8 & 1.305 & 84 & 3.5 \\
\hline 20 & 1.866 & 97.8 & 16.3 & 1.866 & 105.6 & 8.8 & 1.866 & 96 & 4 \\
\hline 30 & 2.189 & 103.2 & 17.2 & 2.189 & 112.8 & 9.4 & 2.189 & 103.2 & 4.3 \\
\hline 50 & 2.592 & 109.8 & 18.3 & 2.592 & 121.2 & 10.1 & 2.592 & 110.4 & 4.6 \\
\hline
\end{tabular}


The IDF Curves for the city of Kumasi were then developed by plotting the rainfall intensity values, $I_{T}$ against corresponding durations, $t_{d}$ for the different return periods. The IDF Curves for the city of Kumasi is presented in figure 2 .

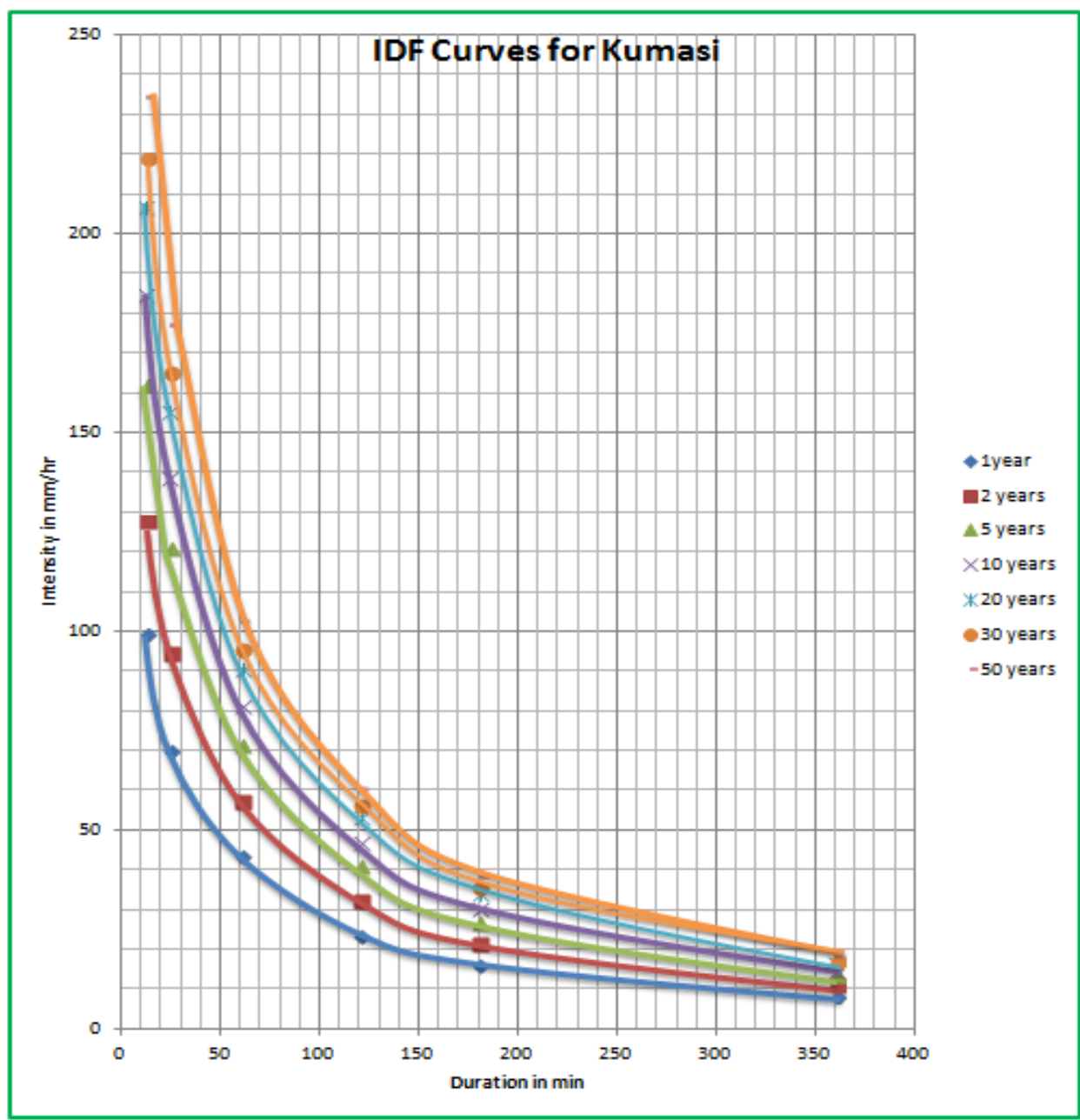

Figure2: IDF curves for Kumasi

The IDF estimates resulting from this study (Figure 2 and Table 3) are in accordance with the general properties of IDF curves. Thus for the same return period, high intensities are related to short durations and secondly, the curves are parallel; they do not cross each other.

\subsection{Comparison of New IDF estimates and Existing Dankwa [7] IDF estimates for Kumasi City}

Comparing the IDF results in this study to the existing Dankwa [7] IDF estimates for Kumasi, there are variations in the intensities. In order to picture the degree of variation, the new IDF estimates and the existing Dankwa [7] IDF estimates and their incremental rate of change are presented in table 3 below.

Table 3: Comparison of New IDF estimates and Dankwa [7] IDF estimates for Kumasi City

\begin{tabular}{|c|c|c|c|c|c|c|c|c|c|c|c|c|}
\hline & \multicolumn{3}{|l|}{5 Year } & \multicolumn{3}{|l|}{10 Year } & \multicolumn{3}{|l|}{25 Year } & \multicolumn{3}{|l|}{50 Year } \\
\hline & ankwa & New & $\%$ incr. & Dankwa & New & $\%$ incr. & Dankwa & New & $\%$ incr. & Dankwa & New & $\%$ incr. \\
\hline $12 \mathrm{~min}$ & 137.2 & 161.6 & +17.8 & 153.7 & 184.4 & +20.0 & 176.5 & 213.2 & +20.8 & 191.8 & 234.5 & +22.3 \\
\hline $24 \mathrm{~min}$ & 118.1 & 120.7 & +2.2 & 127.0 & 138.3 & +8.9 & 154.9 & 160.5 & +3.6 & 170.2 & 177.0 & +4.0 \\
\hline $42 \min$ & 93.7 & 75.4 & -19.6 & 104.1 & 84.8 & -18.5 & 122.9 & 96.7 & -21.3 & 134.9 & 105.5 & -21.8 \\
\hline $1 \mathrm{hr}$ & 77.2 & 71.3 & -7.7 & 83.8 & 81.0 & -3.3 & 101.9 & 93.3 & -8.4 & 112.0 & 102.3 & -8.7 \\
\hline $2 \mathrm{hrs}$ & 45.7 & 41.0 & -10.3 & 53.3 & 47.0 & -11.8 & 64.8 & 54.6 & -15.7 & 73.7 & 60.3 & -18.2 \\
\hline $3 \mathrm{hrs}$ & 33.0 & 26.6 & -19.4 & 38.6 & 30.2 & -21.8 & 45.2 & 34.8 & -23.0 & 50.3 & 38.2 & -24.1 \\
\hline $6 \mathrm{hrs}$ & 19.3 & 13.1 & -32.1 & 22.9 & 14.7 & -35.8 & 27.4 & 16.8 & -38.7 & 30.7 & 18.3 & -40.4 \\
\hline $12 \mathrm{hrs}$ & 10.4 & 6.8 & -34.7 & 12.4 & 7.8 & -37.1 & 15.2 & 9.1 & -40.1 & 17.3 & 10.1 & -41.6 \\
\hline $24 \mathrm{hrs}$ & 5.3 & 3.1 & -41.8 & 6.4 & 3.5 & -45.3 & 7.9 & 4.1 & -48.1 & 8.9 & 4.6 & -48.3 \\
\hline
\end{tabular}


The results obtained indicate that:

- The New IDF estimates are higher for shorter durations. The percentage increase ranges between $2 \%$ and $25 \%$.This might be as a result of low precipitation trends for shorter durations in 1970s.

- New IDF estimates are lower for longer durations. The percentage decrease ranges between 3\% and $49 \%$. This might be as a result of high precipitation trends for longer durations in 1970s.

\section{CONCLUSION AND RECOMMENDATION}

This work involves the revision of the Rainfall Intensity Duration Frequency (IDF) Curves for the city of Kumasi. Annual Maximum Rainfall depths of various durations over twenty-two years for Kumasi were subjected to frequency analysis to determine the distribution of which best characterize the data set. The annual maximum series were found to be drawn from the Gumbel distribution whose parameters were computed by fitting the statistics to the data. The Chi-square test and the Kolmogorov-Smirnov test prove the appropriateness of the fitting.

The IDF estimates resulting from this work have been compared with the existing IDF curves prepared by Dankwa [7]. The results show that for shorter durations (12 min and $24 \mathrm{~min}$ ), the new IDF Curves give higher intensities for the same return period; the percentage increase ranges between $2 \%$ and $25 \%$, whiles for longer durations (42min, $1 \mathrm{hr}, 2 \mathrm{hr}, 3 \mathrm{hr}, 6 \mathrm{hr}, 12 \mathrm{hr}$ and $24 \mathrm{hr}$ ), the new IDF Curves give lower intensities for the same return period with the percentage decrease ranging between 3\% and $49 \%$ when compared with the existing Dankwa [7] IDF Curves. This might be as a result of low precipitation trends for shorter durations and high precipitation trends for longer durations in 1970s and before.

These therefore call for the revision and updating of the existing Dankwa [7] IDF Curves for all the major cities and towns in Ghana to take into account the effect of climate change.

\section{REFERENCES}

[1]. V.T. Chow, Handbook of Applied Hydrology (McGraw-Hill Book, 1988).

[2]. B.S. Dupont, and D.L. Allen, Revision of the Rainfall Intensity Duration Curves for the Commonwealth of Kentucky, Kentucky Transportation Center, College of Engineering, University of Kentucky, USA, 2000

[3]. C.L. Chen, Rainfall intensity-duration-frequency formulas, Journal of Hydraulic Engineering, 109(12), 1983, 1603-1621.

[4]. P.S. Yu, T.C. Yang, and C.S. Lin, Regional rainfall intensity formulas based on scaling property of rainfall, Journal of Hydrology, 295(1), 2004, 108-123

[5]. B. Mohymont, G.R. Demaree, and D.N. Faka, Establishment of IDF Curves for Precipitation in the Tropical Area of Central AfricaComparison of Techniques and Results, Natural Hazards and Earth System Science,4(3), 2004, 375-387.

[6]. L. Oyebande, Deriving rainfall intensity-duration-frequency relationships and estimates for regions with inadequate data, Hydrological Sciences Journal, 27(3), 1982, 353-367.

[7]. J.B. Dankwa, Maximum Rainfall Intensity Duration Frequencies in Ghana, Ghana Meteorological Services Department, 1974.

[8]. A. Mailhot, S. Duchesne, D. Caya, and G. Talbot, Assessment of future change in intensity-duration- frequency (IDF) curves for Southern Quebec using the Canadian Regional Climate Model (CRCM), Journal of hydrology, 347(1), 2007, $197-210$.

[9]. P. Prodanovic, and S.P. Simonovic, Impacts of changing climatic conditions in the Upper Thames River Basin, Canadian Water Resources Journal, 32(4), 2007, 265-284

[10]. World Weather Information Service-Kumasi, World Meteorological Organization, Retrieved 14 June 2015.

[11]. WARM, Ghana's Water Resources, Management Challenges and Opportunities, Water Resources Management Study, Government of Ghana, Accra. 1998. 